\title{
GELATIN AS A CORROSION BIOINHIBITOR AT SALINE MEDIA FROM FISH BONE OF MACKEREL (Scomberomorus sp)
}

\author{
Fataa Kusumattaqiin ${ }^{1,}$, Bagus Agam Pradana ${ }^{1}$, Abdul Halim ${ }^{2}$ \\ ${ }^{1}$ Department of Chemical Engineering, Politeknik Negeri Samarinda, \\ East-Kalimantan, Indonesia \\ ${ }^{2}$ Department of Mechanical Engineering, Politeknik Negeri Samarinda, \\ East-Kalimantan, Indonesia \\ ${ }^{\circledR}$ Corresponding Author: fataakusumattaqiin@polnes.ac.id
}

\begin{abstract}
The purpose of this work was to learn gelatin addition to ferrous coupons at saline medium in inhibiting the corrosion process. Gelatin was produced from the fish bone of Mackerel (Scomberomorus $s p$ ) by several steps namely preparation of the raw material, demineralization, and extraction. It has been investigated that the corrosion rate declined when a higher concentration of gelatin was given. FT-IR explained the formation of protective gelatin on the metal surface. It could be concluded from the typical gelatin wavenumber especially at $1630 \mathrm{~cm}^{-1}$ amide I vibration $(\mathrm{C}=\mathrm{O})$, at $1533 \mathrm{~cm}^{-1}$ amide II vibration $(\mathrm{N}-\mathrm{H})$, at $1242 \mathrm{~cm}^{-1}$ and $3281 \mathrm{~cm}^{-1}$ for amide III (C-N and N-H stretching vibrations). UV-Vis spectroscopy revealed the existence of peptide bonds (200-250 $\mathrm{nm})$ and chromophores (250-300 nm). In addition, SEM- EDX analysis explained that a smoother surface and a protective film were formed with the addition of gelatin.

Keywords: Gelatin, Bioinhibitor, Scomberomorus sp, Corrosion Rate, Protective Film
\end{abstract}

RASĀYAN J. Chem., Vol. 14, No.4, 2021

\section{INTRODUCTION}

Extraction of gelatin could be carried out by hydrolyzing collagen from a certain body part of the animal. The heating process of collagen resulting in a mixture of protein and a broken peptide bond of various sizes. ${ }^{1}$ Gelatin consists of a protein mostly containing glycine, proline and 4-hydroxyl proline amino acid residues. ${ }^{2}$ Amino acids composition in gelatin are equal to collagen. But it has different properties especially in rheology, emulsifying and gel properties. ${ }^{2}$ Because of its unique properties, gelatin has already been applied for many purposes such as in food, pharmaceutical, tissue engineering, or even in anti-corrosion needs. ${ }^{3,4}$ On the same hand, the broad usages are supported by abundant raw materials and cheap prices of gelatin. ${ }^{5}$

Corrosion is indicated by the decadence of structural material as a result of interactions with around environment. ${ }^{5}$ There are a lot of methods to maintain structural material from corrosion, like the cathodic cover, coating, the use of anti-corrosion material and participation of inhibitor. ${ }^{6}$ In general, a biological compound that already existed in nature could be used as a potential bioinhibitor. ${ }^{7-14}$ The addition of gelatin as a green corrosion inhibitor was already investigated by Haruna et al ${ }^{4}$ in $15 \% \mathrm{HCl}$ as a representative at the acid condition. They discovered that gelatin showed excellent inhibition efficiency. And the surface morphology study expressed the evidence of a protective layer on coupons surface was monitored. In addition, widely application of gelation also was effectively employed at another metal surface such as aluminum at sodium hydroxide circumstance. ${ }^{15}$ Besides that, the preparation of gelatin as microgels was successfully observed could extend the coating lifetime. ${ }^{16}$ Infrequent publication of the usage of gelatin from the fish bone of Mackerel (Scomberomorus $s p$ ) as a corrosion bioinhibitor causing this research is quite interesting.

\section{EXPERIMENTAL}

Local fish Mackerel (Scomberomorus sp) was used as a source of gelatin. Hydrochloric acid and sodium chloride were technical grades. Meanwhile, ferrous coupons were prepared to investigate the corrosion formation. 
RASĀYAN J. Chem.

Vol. 14 | No. 3 |2177-2182 | October - December | 2021

\section{Extraction of Gelatin}

Fishbone was cleaned by using tap water, boiled for 30 minutes and cut in small sizes $(2-3 \mathrm{~cm})$. Hydrochloric acid 5 percent was added for the demineralization process ( 24 hours). Ossein was obtained by these steps. Ossein was washed until neutral and maintained at constant temperature namely at $70^{\circ} \mathrm{C}$ for 4 hours. The obtained gelatin was filtered and dried at $65^{\circ} \mathrm{C}$ for 24 hours.

\section{Corrosion Test}

This test was conducted by using the weight loss method. Coupons were placed in containers with 3.5\% of $\mathrm{NaCl}$. Coupons were soaked at different concentrations of gelatin namely $0,100,200,300$ and 400 ppm. Corrosion rate and efficiency were determined after six days of immersion.

The corrosion rate was calculated by the following equation:

$$
\mathrm{CR}(m p y)=\frac{\mathrm{C} \times \mathrm{W}}{\mathrm{D} \times \mathrm{A} \times \mathrm{T}}
$$

Meanwhile, efficiency followed below calculation:

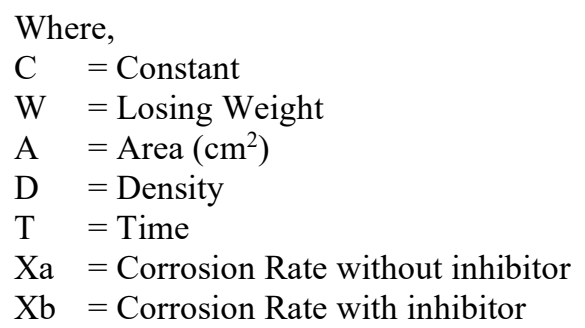

$$
\text { Efficiency }=\frac{\mathrm{Xa}-}{\mathrm{Xa}} \times 100 \%
$$

\section{Characterization}

FT-IR

To study the functional groups, samples were characterized by using FT-IR Attenuated Total Reflection (ATR) method. The spectra were used to forecast whether a cover was formed at the coupon surface and to ensure the extracted gelatin was obtained.

\section{UV-Vis Spectroscopy}

The scanning was processed from $800-200 \mathrm{~nm}$. The effects of bioinhibitor were studied by varying the coupon with gelatin and absence gelatin after 6 days.

\section{SEM-EDX Mapping}

The investigation of surface morphology, element composition and their distribution were informed by SEM-EDX mapping. The ferrous coupons were treated in 0 and $400 \mathrm{ppm}$ of gelatin for six days.

\section{RESULTS AND DISCUSSION}

To evaluate the effect of gelatin in inhibiting the corrosion process, gelatins were varied in several concentrations such as $0,100,200,300$ and $400 \mathrm{ppm}$ at saline media $(3.5 \% \mathrm{NaCl})$.

Figure-1(a) and 1(b) exhibit ferrous coupons at the beginning and after 6 days. Gelatins were organized from low to high concentration from left to right (Fig.-1(a) and (b)). Meanwhile, the extracted gelatin is seen in Fig.-1(c). The extracted gelatin had a brownish granular appearance. The extracted gelatin was easy to be dissolved in water. The yield, ash and moisture content were $4.18 \%, 3.21 \%$ and $8.57 \%$ respectively.

After 6 days, it could be seen that ferrous coupons with a higher concentration of gelatin where the saline media a little bit clear compared to blank coupon $(0 \mathrm{ppm})$. At $0 \mathrm{ppm}$, rust was formed the entire ferrous coupon. And rust level was downtrend from 100 to $400 \mathrm{ppm}$ of gelatin.

In this study, corrosion rate was determined by the weight loss method. The corrosion rate and efficiency are shown in Table-1. 
RASĀYAN J. Chem.

Vol. 14 | No. 3 |2177-2182 | October - December | 2021

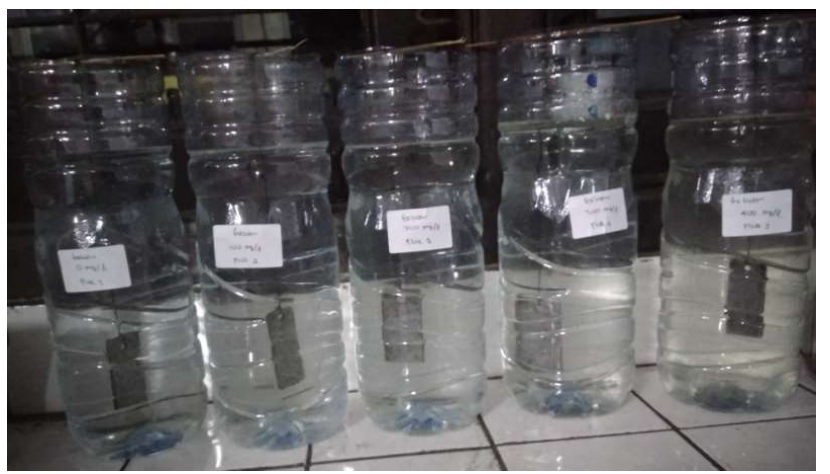

(a)

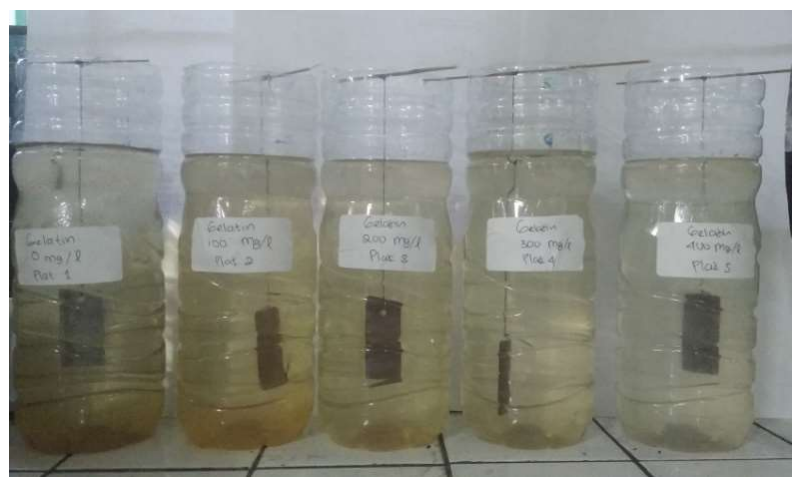

(b)

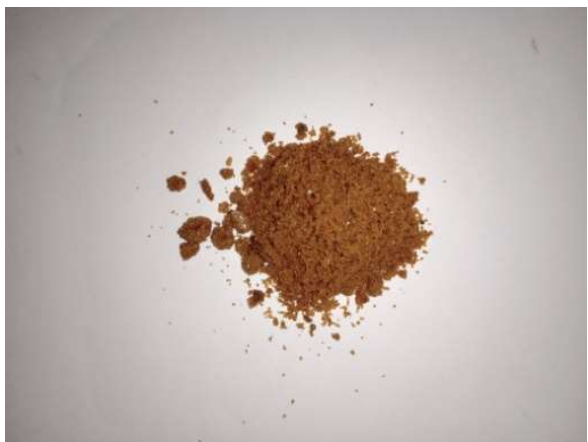

(c)

Fig.-1: Corrosion at Saline Medium (3.5\% NaCl) (a.) Left to right $(0,100,200,300$ and $400 \mathrm{ppm}$ of gelatin on 0 days) (b.) Left to right $(0,100,200,300$ and $400 \mathrm{ppm}$ of gelatin after 6 days) (c.) gelatin

It was found that the corrosion rate reduced significantly when the concentration was added from 0 to 400 ppm. Meanwhile, the efficiency increased steadily when a higher concentration of gelatin in saline media was added. In addition, biological compounds comprising atoms for instance oxygen, sulfur, phosphorus and nitrogen are useful to protect a structural material from corrosion. ${ }^{17,18}$

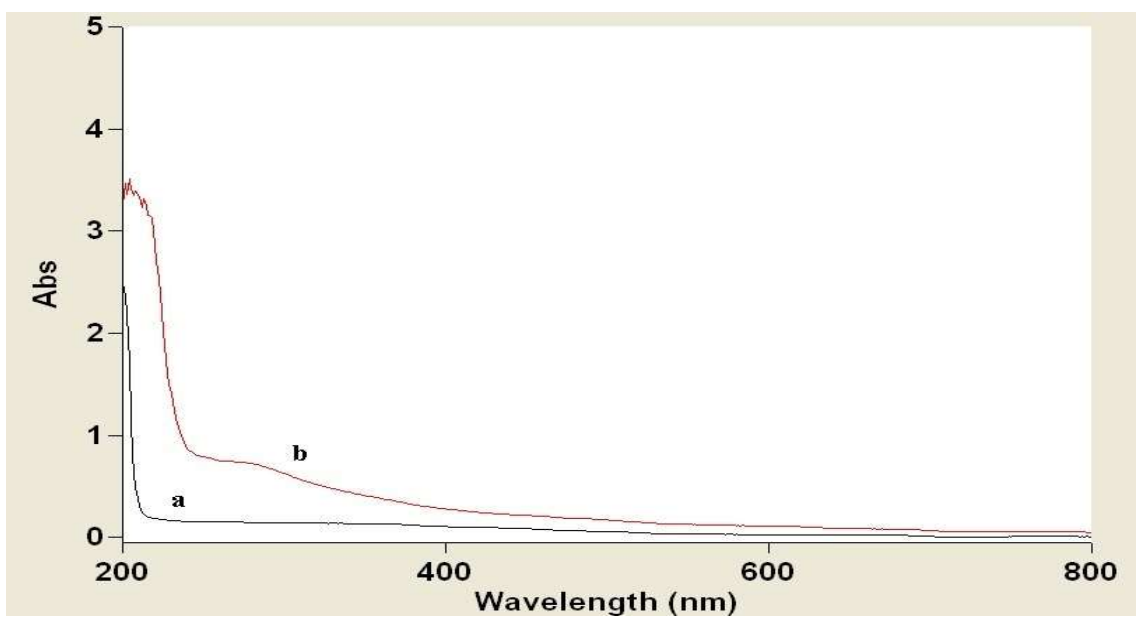

Fig.-2: UV- Visible Spectroscopy of Ferrous Coupon Immersion with Conditions (a)without gelatin after 6 days (b)with gelatin after 6 days (400 ppm)

UV-Vis spectroscopy is used to learn the composition of samples based on electron excitation to antibonding molecular. Peak absorption at longer wavelengths indicates electrons more easily move to higher states. In this study, spectra of ferrous coupon with the absence and presence of gelatin exhibits different pattern spectra. The pattern spectra of condition with gelatin $(400 \mathrm{ppm})$ showed two peaks caused peptide bond ( $\pi \rightarrow \pi^{*}$ transition) and the existence of the aromatic group ( $\rightarrow \pi^{*}$ transition), namely at around 220 and $280 \mathrm{~nm}^{19}$ 
RASĀYAN J. Chem.

Vol. 14 | No. 3 |2177-2182| October - December | 2021

Table-1: Corrosion Rate (mpy) and Efficiency (\%) of Absence and Existence of Gelatin at Saline Media $(3.5 \% \mathrm{NaCl})$

\begin{tabular}{c|c|c}
\hline Gelatin Concentrations (ppm) & Corrosion Rate (mpy) & Efficiency (\%) \\
\hline 0 & 18.8165 & 0 \\
\hline 100 & 16.2812 & 13.47 \\
\hline 200 & 12.6112 & 32.98 \\
\hline 300 & 10.1090 & 46.28 \\
\hline 400 & 7.7736 & 58.69 \\
\hline
\end{tabular}

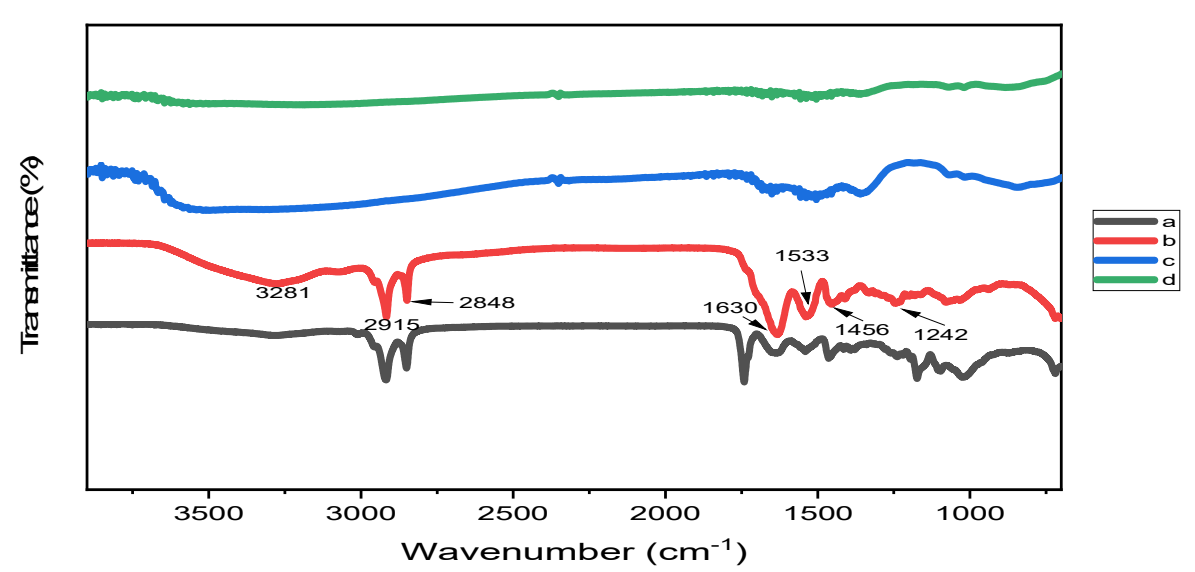

Fig.-3: FT-IR Spectra of (a) Fish Bone (b) Extracted Gelatin (c) Ferrous Coupon with Bioinhibitor (400 ppm) and (d) Ferrous Coupon without Bioinhibitor (0 ppm)

The existence of gelatin was investigated by FT-IR analysis. FT-IR could be used to gather functional group information after extraction and corrosion tests. Spectra of fishbone, the extracted gelatin and coupon with bioinhitor show amide I vibration $(\mathrm{C}=\mathrm{O})$ at $1630 \mathrm{~cm}^{-1}$, amide II vibration $(\mathrm{N}-\mathrm{H}) 1533 \mathrm{~cm}^{-1}$, $1242 \mathrm{~cm}^{-1}$ and $3281 \mathrm{~cm}^{-1}$ for amide III (C-N and N-H stretching vibrations respectively). ${ }^{20-22}$ Meanwhile, bands at 3281, 2915 and $2848 \mathrm{~cm}^{-1}$ are correlated to amide $\mathrm{N}-\mathrm{H}$ stretching, C-H sp ${ }^{3}$ asymmetric and symmetric vibration successively. From FT-IR analysis, gelatin has already been absorbed on coupon inhibiting corrosion process.

The rust formation is studied by using SEM. Surface analysis revealed a smoother surface appearance at the ferrous coupon in the presence of gelatin (Fig.- 4). It was caused by a protective layer formation as the attendance of gelatin molecules. ${ }^{23-25}$

Figure-5 exhibits Energy Dispersive X-Ray (EDX) and element mapping analyses at ferrous coupons. These analyses showed the existence of some elements such as carbon $(\mathrm{C})$, oxygen $(\mathrm{O})$, iron $(\mathrm{Fe})$ and chloride $(\mathrm{Cl})$ in the absence of gelatin at ferrous coupon. But, the presence of gelatin causing chloride $(\mathrm{Cl})$ content disappeared dramatically. These evidence describing a protective layer at the ferrous coupon layer was formed. ${ }^{4}$

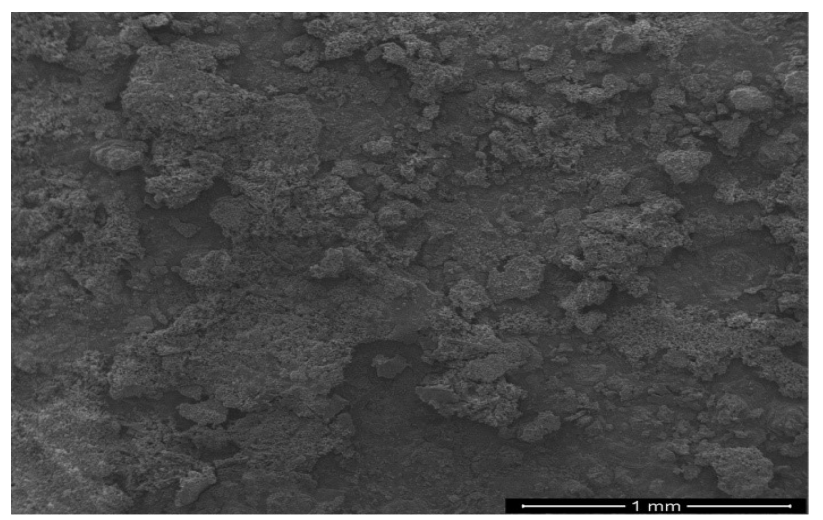

(a)

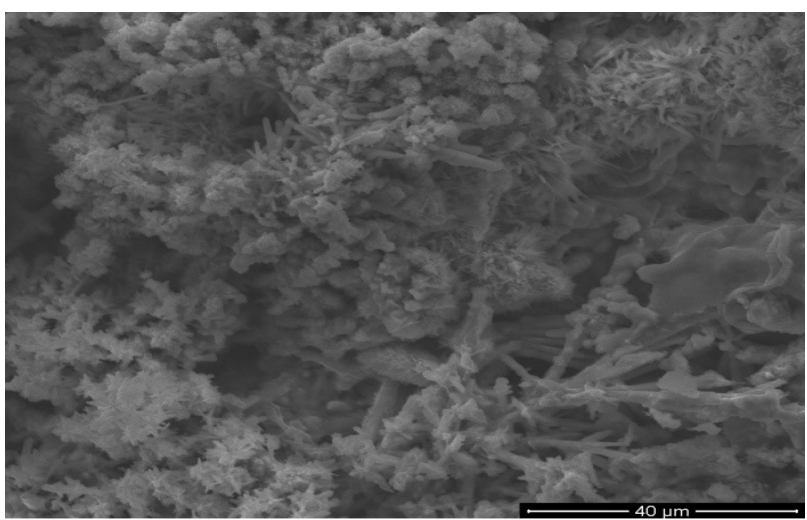

(b) 
RASĀYAN J. Chem.

Vol. 14 | No. 3 |2177-2182 | October - December | 2021

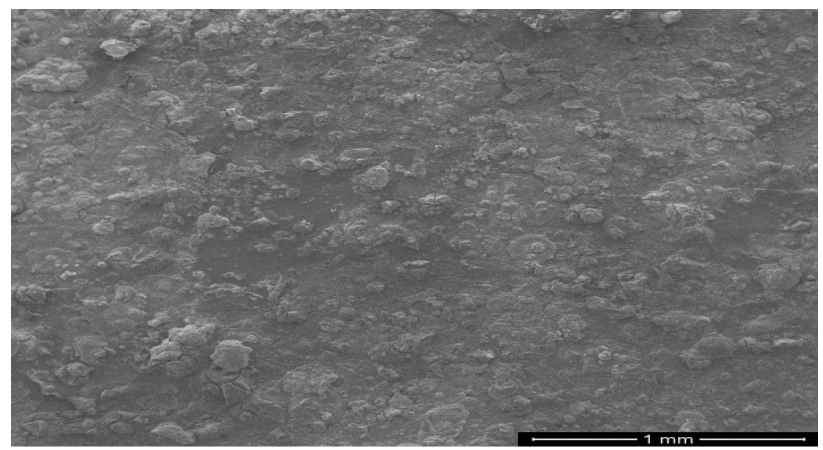

(c)

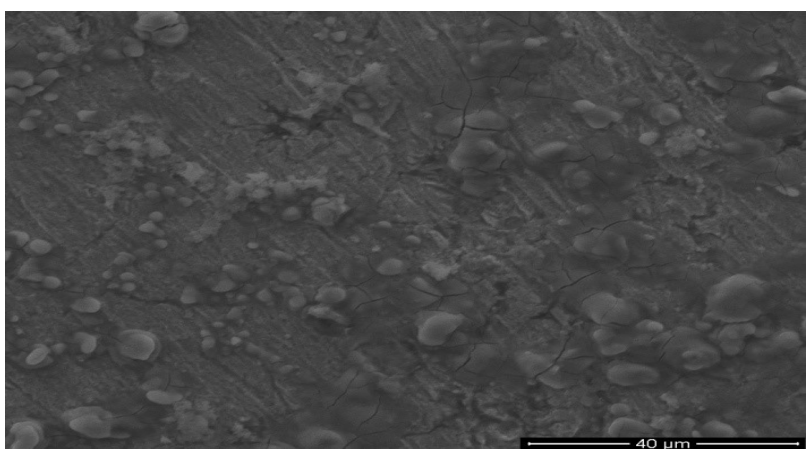

(d)

Fig.-4: SEM analysis (a) Magnification $100 \mathrm{X}$ at ferrous coupon without gelatin (b). magnification $2500 \mathrm{X}$ at ferrous coupon without gelatin (c) magnification $100 \mathrm{X}$ at ferrous coupon with gelatin $400 \mathrm{ppm}$ and (d) magnification 2500 $\mathrm{X}$ at ferrous coupon with gelatin $400 \mathrm{ppm}$

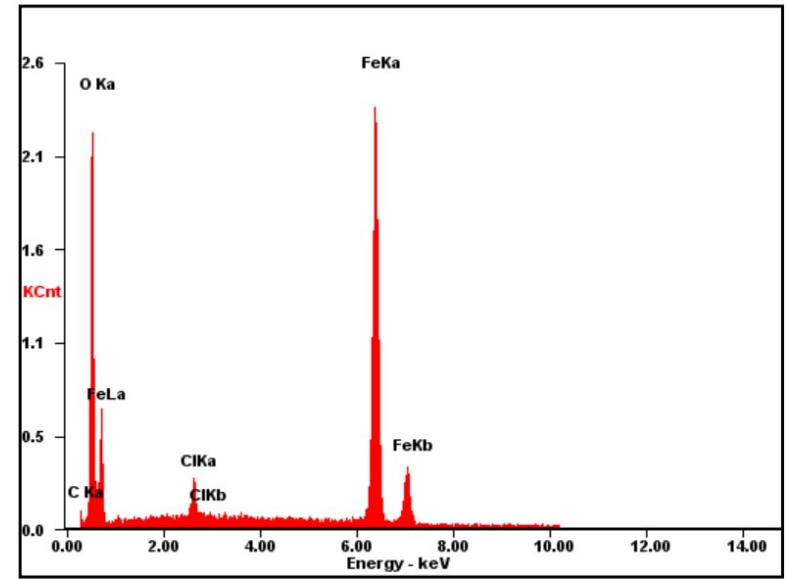

(a)

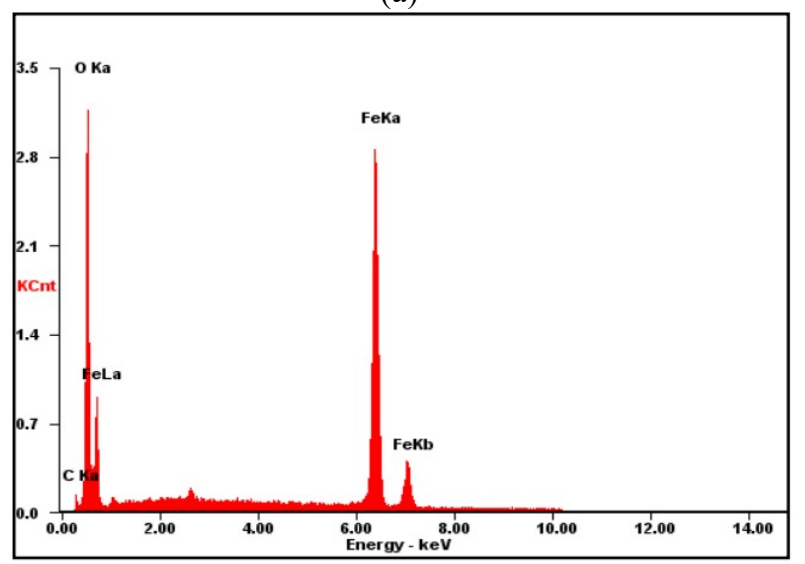

(c)

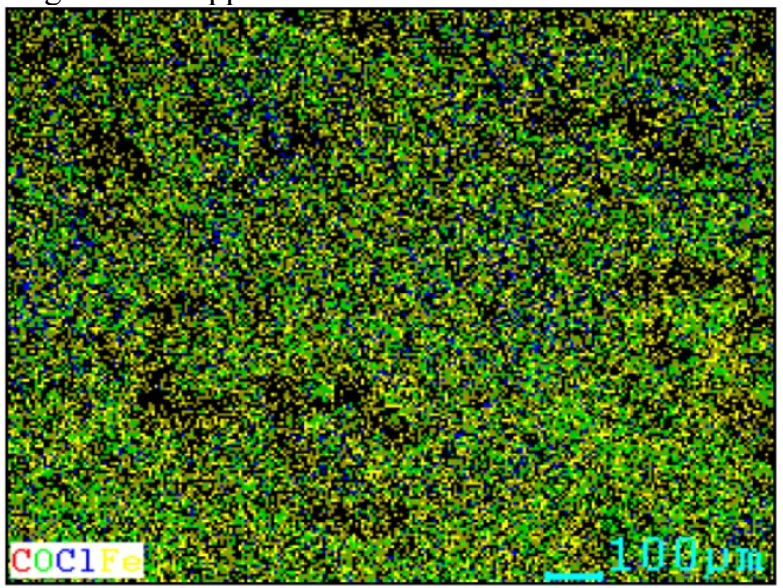

(b)

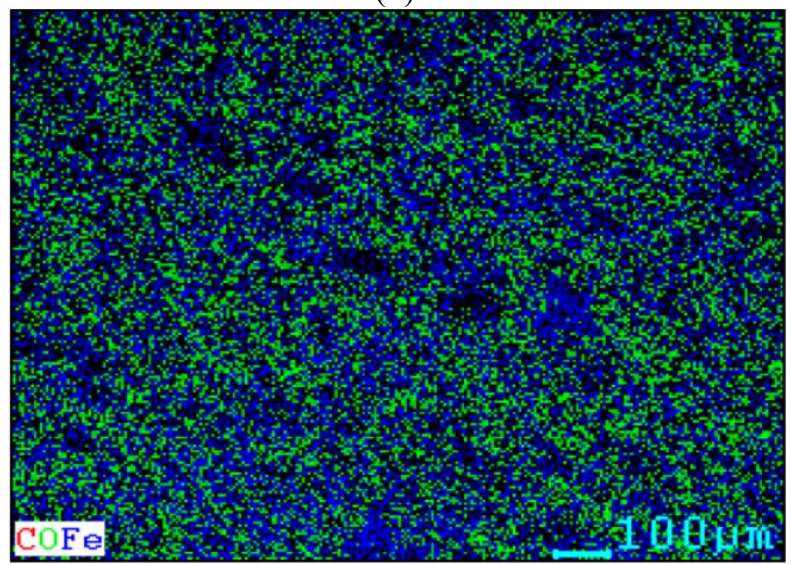

(d)

Fig.-5: Energy Dispersive X-Ray (EDX) (a) Element Analysis at Ferrous Coupon without Gelatin (b) Element Mapping at Ferrous Coupon without Gelatin (c) Element Analysis at Ferrous Coupon with Gelatin and (d) Element Mapping at Ferrous Coupon with Gelatin

\section{CONCLUSION}

FT-IR and UV-Vis Spectroscopy and SEM-EDX analysis exhibited the formation of the gelatin layer at ferrous coupon. It was found the typical spectra amide I, amide II and amide III at FT-IR analysis. On the same hand, peptide bond and aromatic groups were observed at UV-Vis Spectroscopy. Meanwhile, SEMEDX analysis showed a smoother and certain element (chlorine) vanished when gelatin was added. All 
RASĀYAN J. Chem.

Vol. 14 | No. 3 |2177-2182 | October - December | 2021

characterizations were supported by the physical appearance of ferrous coupons. When a higher concentration of gelatins was added to the container, the formation of rust was in a decreasing trend.

\section{REFERENCES}

1. L.-C. Lva, Q.-Y. Huanga, W. Dinga, X.-H. Xiaoa, H.-Y. Zhang, and L.-X. Xiong, Functional Foods, 63, 1(2019), https://doi.org/10.1016/j.jff.2019.103581

2. A. Duconseille, T. Astruc, N. Quintana, F. Meersman, and V. Sante-Lhoutellier, Food Hydrocoll, 43, 360(2015), https://doi.org/10.1016/j.foodhyd.2014.06.006

3. L.-C. Lv, Q.-Y. Huang, W. Ding, X.-H. Xiao, H.-Y. Zhang, and L.-X. Xiong, Journal of Functional Foods, 63(2019), https://doi.org/10.1016/j.jff.2019.103581

4. K. Haruna, I.B. Obot, N.K. Ankah, A.A. Sorour, and T.A. Saleh, Journal of Molecular Liquids, 515(2018), https://doi.org/10.1016/j.molliq.2018.05.058

5. K. Rajithaa, Kikkeri Narasimha Shetty Mohanaa, A. Mohananb, and A.M. Madhusudhana, Colloids and Surfaces, 587, 124341(2020), https://doi.org/10.1016/j.colsurfa.2019.124341

6. D. Dwivedi, K. Lepková, and T. Becker, The Royal Society of Chemistry Advances, 7(2017), https://doi.org/10.1039/C6RA25094G

7. F. Deflorian and I. Felhosi, Corrosion, 59, 112(2003), https://doi.org/10.5006/1.3277540

8. S.M. Powell, H.N. Mcmurray, and D.A. Worsley, Corrosion, 55, 1040(1999), https://doi.org/10.5006/1.3283941

9. M.A. Quraishi and D. Jamal, Corrosion, 56, 983(2000), https://doi.org/10.5006/1.3294388

10. M.A. Migahed, M. Abd-El-Raouf, A.M. Al-Sabagh, and H.M. Abd-El-Bary, Electrochim, 50, 4683(2005), https://doi.org/10.1016/j.electacta.2005.02.021

11. P. Bommersbach, C. Alemany-Dumont, J.P. Millet, and B. Normand, Electrochim. Acta, 51, 1076(2005), https://doi.org/10.1016/j.electacta.2005.06.001

12. T. Zaiz and T. Lanez, Chemical and Pharmaceutical. Research, 4, 2678(2012), https://doi.org/10.1016/j.corsci.2007.09.002

13. G. Blustein, A.R.D. Sarli, J.A. Jaén, R. Romagnoli, and B.D. Amo, Corrossion. Science, 49, 4202(2007), https://doi.org/10.1016/j.corsci.2007.05.008

14. A. Bouyanzer, B. Hammouti, and L. Majidi, Materials Letters, 60, 2840(2006), https://doi.org/10.1016/j.matlet.2006.01.103

15. M. Abdallah, E.M. Kamar, A.Y. El-Etre, and Salah Eid, Physicochemical Problems of Materials Protection, 52, 140(2016), https://doi.org/10.1134/S2070205116010020

16. A. Stankiewicz, Z. Jagoda, K. Zielinska, and I. Szczygiel, Materials and Corrosion, 66, 1391(2015), https://doi.org/10.1002/maco.201508436

17. M.A. Deyab, Corrossion Science, 49(5), 2315(2007), https://doi.org/10.1016/j.corsci.2006.10.035

18. A.M. Alsabagh, M.A. Migahed, and H.S. Awad, Corrosions. Science, 48(2006), https://doi.org/10.1016/j.corsci.2005.04.009

19. J.M. Antosiewicz and a. Shugar, Biophysical Reviews, 8, 163(2016), https://doi.org/10.1007/s12551016-0197-7

20. Y. Piao and B. Chen, International Journal of Biological Macromolecules, 101, 791(2017), https://doi.org/10.1016/j.ijbiomac.2017.03.155

21. Y. Yan, X. Zhang, H. Mao, Y. Huang, Q. Ding, and X. Pang, Applied Surface Science, 329, 76(2015), https://doi.org/10.1016/i.apsusc.2014.12.115

22. X. Shan, X. Guo, Y. Yin, Y. Miao, and H. Dong, Colloids and Surfaces A: Physicochemical and Engineering Aspects, 520, 420(2017), https://doi.org/10.1016/j.colsurfa.2017.01.077

23. S. Karim, C.M. Mustafa, M. Assaduzzaman, and M. Islam, Chemical Engineering Research Bulletin, 14, 87(2010), https://doi.org/10.3329/cerb.v14i2.4813

24. D. Jayaperumal, Materials Chemistry and Physics, 119, 478(2010), https://doi.org/10.1016/j.matchemphys.2009.09.028

25. U.F. Ekanem, S.A. Umoren, I.I. Udousoro, and A.P. Udoh, Materials Science, 45, 5558(2010), https://doi.org/10.1007/s10853-010-4617-y

[RJC-6414/2021] 